\title{
Vitalidades sensuais. Modos não corpóreos de sentir e conhecer na Amazônia indígena ${ }^{1}$
}

\author{
Fernando Santos-Granero
}

\section{Smithsonian Tropical Research Institute}

RESUMO: Os Yanesha da Amazônia peruana concordariam com Aristóteles e São Tomás de Aquino: só se pode chegar ao conhecimento pela via da percepção sensorial. Yanesha e filósofos, entretanto, não entrariam em acordo quanto ao que, exatamente, significa "percepção sensorial". Na tradição ocidental, os sentidos constituem a dimensão "fisiológica" da percepção. Só podemos conhecer, afirma-se, por meio do corpo e dos sentidos: visão, audição, olfato, tato e paladar. Os Yanesha, por outro lado, consideram os sentidos corporais como meios de conhecimento imperfeitos, incapazes de apreender a dimensão verdadeira, espiritual, do mundo. Apenas um dos componentes não corpóreos da pessoa, yecamquën - ou "nossa vitalidade" -, é dotado das faculdades sensoriais que possibilitam uma percepção correta e, com ela, um conhecimento "verdadeiro". É por isso que, do ponto de vista yanesha, as vitalidades são sensuais, ou sensoriais, ao passo que os corpos, em certa medida, são insensíveis. Este artigo trata dos modos não corpóreos de sensorialidade e conhecimento dos Yanesha, assim como de suas teorias da percepção e de suas hierarquizações dos sentidos; com ele, meu propósito é defender uma renovada antropologia dos sentidos no âmbito dos estudos amazônicos, propondo uma revisão crítica da noção de perspectivismo ameríndio.

PALAVRAS-CHAVE: Amazônia, Peru, Yanesha, pessoa, percepção sensorial, perspectivismo. 
No domínio das teorias da percepção dos Yanesha, a primeira lição que recebi foi durante uma pescaria no rio Palcazu, no leste do Peru, numa noite escura de maio de 1977. Estudante, em minha primeira pesquisa de campo, eu estava com os Yanesha havia menos de dois meses. $\mathrm{Na}$ pesca noturna, acompanhava-me Matar, o chefe tradicional da localidade de Camantarmas que se convertera, por opção própria, em meu mentor. Cansado de tantas perguntas, e do fato de minha linha insistir em se enroscar na sua, Matar sugeriu que eu me afastasse um pouco dele, dirigindo-me a um ponto que, com excessivo entusiasmo, assegurou excelente para pescar. Foi o que fiz. Lá estava eu, em absoluta solidão, a mascar folhas de coca e a fumar continuamente para dissipar o tédio, quando uma bela cantoria chegou aos meus ouvidos. A canção era uma sherareñets, estilo feminino dos cantos sagrados coshaññats. Ao acompanhar as vocalistas, reconheci o requërqueñets, toque sagrado da flauta de Pã. Os sons agudos de duas flautas principais e as notas mais graves de muitas outras no acompanhamento combinavam-se suavemente com as vozes em registro soprano.

Naquele tempo, a sinuosidade do rio Palcazu ainda dificultava minha orientação espacial, mas tive quase certeza de que na margem oposta, bem à frente do ponto onde eu me reinstalara para pescar, vivia Shecor, irmão mais velho de Matar. Enquanto escutava aquela música cativante, lembrei que a filha de Shecor, tendo menstruado pela primeira vez, entrara em confinamento ritual poucas semanas antes. $\mathrm{O}$ término do estado de reclusão da garota estava previsto para a próxima lua cheia, e seus pais disseram que gostariam da minha presença na festa que então ocorreria. Diante do que parecia ser uma antecipação da realização do evento, fiquei intrigado e algo desapontado por não ter sido convidado.

Depois de um certo tempo de escuta da música, decidi perguntar a Matar se ele sabia algo sobre a festa. Minha questão desconcertou-o: "Que festa?", retrucou. "Essa na casa do Shecor, do outro lado do rio" 
Revista de Antropologia, São Paulo, USP, 2006, v. 49 no 1.

- respondi. "Você não está ouvindo a música?" Matar, com uma expressão de embaraço e inquietude ainda maior, disse-me que do outro lado do rio não vivia ninguém e que ele próprio não ouvia música alguma. Pensei em dissimulação: diria não ouvir a música para aliviar meu abatimento de quem não fora convidado para a festa. Porém, suas atitudes seguintes revelaram que dissimulação ali não havia: apressou-me a recolher a linha de pesca e a preparar a partida. Quando perguntei o motivo, pediu que eu ficasse quieto. Juntamos nossas coisas com apuro, pulamos para dentro da canoa e rumamos rio abaixo em absoluto silêncio, até chegar ao atracadouro de Matar.

Suas palavras sobre o ocorrido vieram apenas na segurança do lar. Ao pé do fogo, com um novo punhado de folhas de coca na boca, disse que eu não ouvira vozes humanas, mas, sim, o canto de Pocoy, uma espécie de seres que vivem sob as águas fluviais, a quem os Yanesha chamam, em espanhol, sirenas (sereias). Escutar as Pocoy, contou-me, é um evento raro e muito perigoso. Normalmente, as sereias são imperceptíveis a quem está desperto, só se revelam a pescadores solitários com o propósito de seduzi-los. Se um pescador desavisado dá ouvidos ao atraente canto de uma Pocoy e a chama, ela se lhe apresenta em forma de mulher - branca, bela e loira. Encontros desse tipo são geralmente fatais. Pocoy aparece lindamente pintada, vestida com uma túnica cintilante e adornada com colares de sementes aromáticas; fala em tom carinhoso, é doce ao paladar e macia ao toque. Subjuga, assim, os sentidos do homem escolhido, que, iludido pelos ardis da sereia, perde sua vontade própria. A partir daí, o homem encontra-se enfeitiçado por Pocoy, cujo único desejo é poder carreá-lo, como amante, para o mundo subaquático.

Eis por que Matar mostrara-se tão ansioso em partir: se eu não tivesse ido embora enquanto ainda senhor de minha própria vontade, disseme ele, poderia ter sido tentado a me comunicar com a sereia; em caso de havê-lo feito, não conseguiria voltar para casa nunca mais. $\mathrm{O}$ que 
exatamente aconteceu naquela noite eu não sei. Ouvira, de fato, a gente subaquática? Experimentara uma alucinação auditiva? Ou se tratara de uma trapaça dos meus sentidos? O que quer que tenha sido, a ocasião muito me ensinou acerca dos modos yanesha de entender o mundo e, sobretudo, de percebê-lo por meio dos sentidos - e eu estava por aprender ainda mais nos meses seguintes.

Neste artigo, apresento os princípios mais importantes da teoria yanesha da percepção e do conhecimento, discutindo como ela contrasta, de maneiras significativas, com a nossa. Meu propósito é defender uma renovada antropologia dos sentidos para os estudos amazônicos (ver Howes, 1991, 2005) e propor uma revisão crítica da noção de perspectivismo ameríndio. Ao proceder assim, vou na companhia daquele que considero um dos argumentos mais consistentes de Joanna Overing na coletânea Reason and Morality (1985), por ela editada: “À humildade só se chega por familiarização com as epistemologias e ontologias de outras culturas - familiarização que depende de etnografia cuidadosa, obtida ao levar a sério as afirmações de outros sobre seus próprios mundos sociais". Tenho seguido, desde então, esse sábio preceito.

\section{A pessoa e seus componentes}

As idéias dos Yanesha sobre a pessoa e a sensorialidade são muito mais complexas do que aquelas que prevalecem nas sociedades ocidentais. Segundo suas noções, cada indivíduo compóe-se de um corpo e de duas entidades incorpóreas: yecamquëñ ("nossa alma/vitalidade") e yechoyeshem ("nossa sombra"). O corpo é concebido como a dimensão material da pessoa. O termo chetsots, que significa tanto corpo como carne, póe em destaque o fato de o corpo ser pura materialidade. Num outro plano, porém, os Yanesha concebem o corpo como uma túnica 
Revista de Antropologia, São Paulo, USP, 2006, v. 49 no 1.

que cobre seus elementos não corpóreos. ${ }^{2}$ Essa concepção remete a certas túnicas de corpo inteiro feitas de algodão, diferenciadas à base de gênero (femininas, cashemuets; masculinas, shetamuets). Até pouco tempo atrás, elas costumavam ser a vestimenta yanesha de todos os dias; atualmente, são usadas na intimidade do lar ou em ocasiões formais. A concepção do que aqui se trata não chega a surpreender, dado que, uma vez envolvidos em suas túnicas, homens e mulheres yanesha tornam-se as próprias túnicas (ver Figura 1).

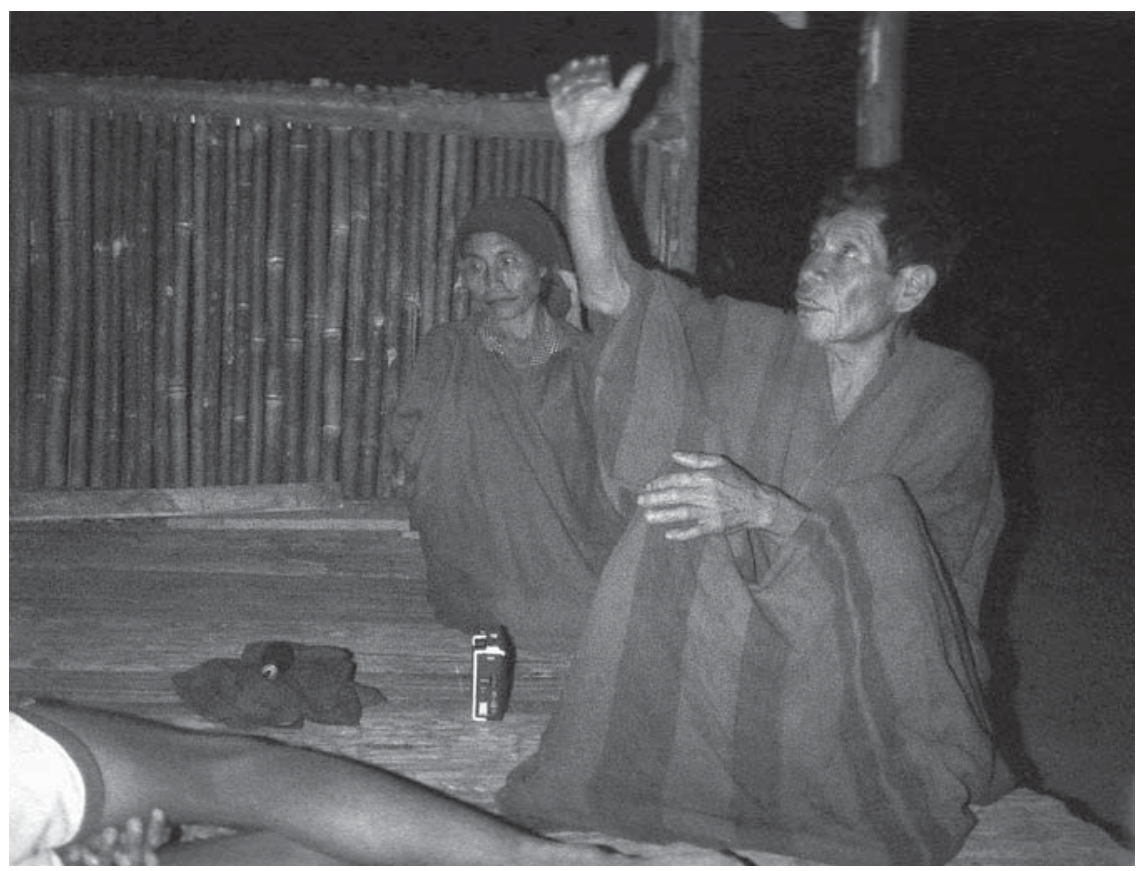

Figura 1: Corpos são túnicas e túnicas são corpos. 
No caso yanesha, ao contrário do que sugere Viveiros de Castro (1998, p. 471) para os ameríndios em geral, a relação entre corpos e túnicas não é metafórica, mas literal: corpos são túnicas e túnicas são corpos. Isso se confirma tanto por narrativas míticas como por convicções relativas ao xamanismo. Ao final dos tempos míticos, os humanos conservaram suas túnicas - no sentido de seus corpos/túnicas humanos -, ao passo que as ornamentadas túnicas de animais, espíritos e outros seres transformaram-se nos seus corpos atuais. Assim, diz-se que a carapaça do tatu, as manchas do jaguar e a pretidão do mutum derivam de padrões e cores de suas túnicas míticas. Em acréscimo, os Yanesha afirmam que, quando os xamãs ingerem substâncias narcóticas ou alucinógenas, suas "almas" viajam a outros níveis cósmicos e suas "túnicas" - novamente, no sentido tanto de corpo como de túnica - ficam para trás. Se ocorre de uma dessas almas viajantes ser aprisionada ou devorada, acredita-se que o corpo do xamã venha a definhar, e ele próprio, a morrer.

A importância do corpo e dos cinco sentidos em face do mundo material, como fontes de informação e meios de comunicação, é levada em conta pelos Yanesha. Entretanto, eles tomam os sentidos corpóreos como incapazes de perceber a dimensão espiritual que subjaz, normalmente em estado oculto, a grande parte do mundo tangível. Nem mesmo xamãs podem perceber a dimensão espiritual das coisas por meio dos sentidos físicos. ${ }^{3}$ Os sentidos, portanto, são concebidos como meios inapropriados à tarefa de aquisição/produção de um conhecimento relevante sobre o mundo. Essa tarefa só pode ser desempenhada pelos componentes não corpóreos da pessoa. Entre estes, porém, residem importantes diferenças quanto à conexão de cada qual com o corpo, às capacidades sensoriais que portam e à aptidão de um e de outro para gerar conhecimento. 
Revista de Antropologia, São Paulo, USP, 2006, v. 49 no 1.

Considera-se que o componente yechoyeshem, "nossa sombra", está permanentemente unido ao corpo, vínculo que só se desfaz com a morte da pessoa. A manifestação visível de yechoyeshem, conforme indicado por seu nome, é a sombra pessoal. Na condição de sombras, que são totalmente dependentes dos corpos que as projetam, yechoyeshem não têm autoconsciência, vontade ou sentidos, e não são, por isso, capazes de perceber o mundo e de gerar conhecimento. Uma sombra só se liberta da tirania do corpo quando sobrevém a morte do indivíduo da qual é parte; somente então adquire vontade própria, ficando com algumas das capacidades sensoriais do corpo ao qual esteve unida. Essas expartes de seres humanos, conhecidas como choyeshemats, ou "sombras errantes", permanecem às vezes nas proximidades do local de vida e morte das pessoas às quais foram ligadas, situação em que perseguem e aterrorizam os vivos.

A contrastar com yechoyeshem está o componente não corpóreo yecamquën, termo que os Yanesha freqüentemente traduzem ao espanhol por nuestra alma ("nossa alma"). Pensa-se em yecamquëñ como algo dotado das mesmas aptidóes sensórias que o corpo. Na realidade, é a alma, acreditam os Yanesha, que imbui o corpo de faculdades sensoriais. Afirmam que yecamquën é a manifestação, em cada indivíduo, da "substância anímica" de divindades criadoras pertencentes às categorias yato' ("nosso avô") e yompor ("nosso pai"). Essa "substância anímica" de natureza divina, camuequeñets, é concebida como algo que tudo abarca - como a originária fonte de vida do universo. Yecamquëñ é, então, a manifestação especificamente humana e pessoal da força vital que os deuses criadores incutem em todos os seres vivos. É essa dimensão não corpórea da pessoa que confere vida ao corpo, possibilitando que ele tenha tanto uma vida sensual como uma vida de pensamentos. ${ }^{4}$ Se fossem desprovidos de yecamquën, os corpos seriam inanimados, mera 
matéria bruta, e guardariam muita semelhança com as túnicas a que se os equipara. Dizem os Yanesha que camuequeñets, a substância anímica divina, compõe-se de sopro/força vital; nessa medida, como tradução do termo yecamquëñ, "nossa vitalidade" é uma expressão mais adequada do que a "nossa alma”.

Há duas manifestações de yecamquëñ. A primeira, a vitalidade propriamente dita, é capaz de se separar do corpo e de se pôr a vagar por este mundo e por outros níveis cósmicos. Ela tem aparência e fisionomia idênticas às da pessoa de que é parte; nesse sentido, pode-se dizer que a pessoa e seus componentes têm, do ponto de vista yanesha, uma natureza fractal (Luciani Kelly, 2001; Mentore, neste volume). No entanto, à diferença de outros povos ameríndios (ver, por exemplo, Rosengren e Werlang, neste volume), os Yanesha insistem em que as vitalidades são feitas de sopro divino/força divina e, portanto, carecem de corporalidade. ${ }^{5}$ Por conta disso, faltam-lhes também fronteiras delimitadoras de si mesmas, o que implica poderem difundir-se por objetos mantidos em contato direto e prolongado com cada indivíduo, a exemplo de ornamentos pessoais. A segunda manifestação de yecamquëñ diferentemente da primeira, é inseparável do corpo. Sob a forma de um homúnculo, está instalada nas pupilas da pessoa da qual é parte (ver Mentore, neste volume). Essa parte não separável, conhecida como pacheñmer - "o seu ser humanóide" -, responsabiliza-se pela guarda do corpo nos momentos em que ele se encontra vulnerável a toda sorte de acidentes e ataques sobrenaturais: quando nossa vitalidade, ao sair em perambulação, deixa-o desprovido de sua fonte de vida.

Assim como o corpo, nossa vitalidade é dotada de capacidades sensórias. Segundo os Yanesha, porém, os sentidos físicos só apanham a túnica das coisas, isto é, sua aparência material, ao passo que os sentidos não corpóreos que são próprios a nossas vitalidades têm a capacidade de perceber as coisas como "realmente são" ou, em outras palavras, a di- 
mensão espiritual das coisas. Em termos perspectivísticos, isso equivale a dizer que tais sentidos não corpóreos podem perceber animais, espíritos e outros seres não humanos do modo como os integrantes dessa série apreendem a si próprios, isto é, como seres humanos. Note-se que, diferentemente de outros povos ameríndios (Viveiros de Castro, 2004b, p. 468), os Yanesha atribuem essa faculdade a todos os seres humanos, não apenas a xamãs, identificando três circunstâncias nas quais nossas vitalidades encontram liberdade para exercer suas capacidades sensórias e, assim, envolver-se em processos de conhecimento: (1) durante o sono; (2) em vigílias rituais; e (3) após a ingestão de narcóticos ou alucinógenos. Da perspectiva ocidental, em tais condiçôes, os sentidos corpóreos estão alterados, entorpecidos, enfraquecidos ou sobreexcitados. Da perspectiva yanesha, eles foram simplesmente deixados para trás junto com o corpo, de modo a permitir a ativação dos sentidos das vitalidades desencorporadas. É importante observar, então, que as teorias yanesha da percepção não se apóiam numa oposição entre corpo e vitalidade, mas, antes, num contraste entre as faculdades sensoriais de vitalidades encorporadas e desencorporadas - ou, como diria Stolze Lima (2000, p. 48 ), "entre a realidade do sujeito e a realidade da sua alma". Desse ponto de vista, nossas vitalidades, yecamquëñ, são aquelas que dotam as pessoas da capacidade de levar uma vida sensória. Entretanto, vitalidades encorporadas só podem apreender a túnica das coisas, ao passo que vitalidades desencorporadas podem apreender sua dimensão espiritual humana.

\section{O corpo e seus sentidos}

Assim como o euro-americano médio, os Yanesha consideram que o corpo está dotado de cinco sentidos básicos: audição (émueñets), visão (enteñets), olfato (mosyeñets), tato (a’plleñets) e paladar (amlleñets). Em 
face da coleta de informações factuais que a vida neste mundo (añe patsro) requer, os cinco são considerados indispensáveis, mas com importâncias desiguais. Os Yanesha acreditam que a visão e a audição são os dois sentidos mais importantes, nisso procedendo como os euro-americanos. Porém, diferentemente destes, e à semelhança de muitos outros povos ameríndios, atribuem maior relevância à audição do que à visão (ver Seeger, 1981; Passes, 1998, 2001 e neste volume; Murphy, 2004; Belaunde, neste volume). Trata-se de uma confirmação da proposição de que, enquanto sociedades letradas privilegiam a visão e aquilo que se dá a ver, sociedades orais tendem a favorecer a audição e aquilo que se dá a ouvir (McLuhan, 1961). Embora essa assertiva tenha sido recentemente contestada (Classen, 2005), não há dúvida de que povos não letrados, em muitos casos, consideram sentidos outros que não a visão como os mais importantes meios de aquisição de conhecimento.

A mim, a importância da audição nunca se apresentou com maior contundência do que em certa ocasião em 1983, durante a segunda etapa de minha pesquisa de campo com os Yanesha. Havendo gravado alguns mitos, eu convidara Mañor a me acompanhar a Lima para me ajudar na tarefa de transcrevê-los e traduzi-los. Trabalhávamos na sala, ao anoitecer, quando vimos um rato correr do jardim para dentro da casa. Saímos à sua captura, mas não sabíamos em qual cômodo havia entrado; averiguamos quartos e banheiros, olhamos embaixo das camas e atrás dos móveis - nada. Foi quando Mañor disse que poderia achá-lo, necessitando, porém, silêncio absoluto. Entrou no primeiro quarto, apagou a luz, fechou a porta e sentou-se calado no escuro; depois de uns dez minutos, saiu, dizendo que lá o rato não estava. Fez o mesmo no segundo quarto, e o resultado foi idêntico. Cinco minutos dentro do terceiro quarto foram suficientes para que ele surgisse anunciando o paradeiro do animal: a gaveta mais alta do armário embutido. À minha pergunta sobre como podia saber aquilo, respondeu que o rato, ao ouvi-lo entrar 
no ambiente, ficara, de início, completamente paralisado, contudo, depois de alguns minutos de silêncio total, sentira-se mais seguro e começara a se mover - sua localização fora denunciada pelo barulho quase inaudível das patas contra o fundo da gaveta.

A visão é o segundo sentido mais importante para os Yanesha. A capacidade de discriminação visual de caçadores e pescadores, tanto de dia como de noite, é de impressionar. Em caçadas diurnas, ali onde eu enxergava apenas a indistinta massa verde de folhagem, eles podiam identificar a presença de um mutum, de um macaco e mesmo de um bicho-preguiça a se mover lentamente, de ponta-cabeça, num galho de árvore. Em pescarias transcorridas ao amanhecer ou ao anoitecer, os Yanesha não tinham dificuldades, mesmo sob a traidora luminosidade desses momentos do dia, para ajustar a vista à refração da água: com seus arpóes de três pontas, eram capazes de acertar alvos posicionados a mais de dois metros de distância. Também quando caçavam à noite, em esperas na mata ou transitando pelo rio a bordo de uma canoa, resultava-lhes pouco problemático divisar com suas lanternas o lampejo nos olhos de animais, ainda que estes estivessem, como às vezes ocorria, vinte metros afastados deles.

O terceiro sentido mais importante é o olfato, que fornece informações proveitosas à caça e a outras atividades de subsistência. Os caçadores yanesha têm um sentido olfativo bastante aguçado. Ao caminhar numa trilha na mata, podem sentir pelo cheiro se há, nas redondezas, alguma palmeira frutificada de certa espécie ou determinada árvore resinosa. Mais importante do que isso é o fato de também poderem dizer que passou um animal pelo caminho - e qual deles, quanto tempo antes. Matar declarava-se especialmente bom como farejador de animais. Um dia, quando andávamos na mata em busca de um tipo de cipó, pude verificar sua habilidade: a dada altura, estancou abruptamente e sinalizou que eu fizesse o mesmo, provou o aroma do ar à sua volta e disse 
que, não fazia muito tempo, um jaguar cruzara a trilha; poucos metros adiante, viríamos a deparar com recentes pegadas de jaguar impressas no chão barrento.

A clareza com que os Yanesha ordenam as importâncias relativas da audição, da visão e do olfato não se estende aos dois sentidos restantes. $\mathrm{O}$ tato é crucial em algumas atividades, a exemplo do que ocorre na cata do peixe-gato. Como esse animal vive de sugar microalgas, está sempre pegado às pedras soltas do fundo do rio. As pessoas que querem apanhálo perambulam, então, pelas partes mais rasas do rio para ir tocando com as mãos as pedras onde o peixe usualmente se encontra. A visão nada ajuda nessa atividade, que depende totalmente do tato: quando sente as escamas, o catador tem de ser rápido ao agarrar o peixe para evitar que ele escorregue de sua mão.

O sentido menos importante para a coleta de informações sobre o mundo natural é, provavelmente, o paladar, que fornece ainda assim dados relevantes para a condução de determinadas atividades. Em outros tempos, as mulheres yanesha excursionavam à mata em busca do tipo de argila mais adequado para trabalhos de cerâmica, recorrendo a provas gustativas e olfativas em suas escolhas. Paladar e olfato são também cruciais na identificação de cultivares, arbustos e ervas de usos medicinal ou mágico, como também ocorre entre os Matsigenka (Shepard, 2004) e os Bororo (Crocker, 1985, p. 160).

Embora considerem os sentidos físicos indispensáveis à práxis humana neste mundo, os Yanesha confiam pouco em sua própria capacidade de apreender o que, para eles, é a verdadeira natureza do mundo e dos seres que o habitam. À semelhança dos Kaxinawa (Kensinger, 1995, p. 237-46; Lagrou, 2000, p. 157 e neste volume) e de outros povos ameríndios para quem o conhecimento reside no corpo, os Yanesha acreditam que o conhecimento/memória habita o coração. ${ }^{6}$ No entanto, deixam bastante claro que os pensamentos (cotapñats) não são produ- 
zidos pelo corpo, mas pela vitalidade, yecamquën, de um indivíduo. A noção ameríndia de que o mundo material é o invólucro de certa dimensão espiritual, importante fonte de conhecimento extraordinário, parece ser tão generalizada nas terras baixas sul-americanas quanto a idéia de que tal dimensão espiritual só pode ser percebida pela alma, ou vitalidade, de uma pessoa. Até mesmo povos ameríndios que dizem que o conhecimento tem sempre um caráter encorporado põem-se de acordo quanto ao fato de a dimensão espiritual do mundo só poder ser apreendida por meio de componentes não corpóreos da pessoa: "Para que alguém possa ver a verdadeira natureza das gentes e das coisas que compõem o mundo natural - diz Kensinger (1995, p. 240) em referência aos Kaxinawa -, deve também entender bedu yushin, o espírito do olho, às vezes também chamado de o real espírito, yushin kuin". Os Yanesha, os Kaxinawa e outros ameríndios sustentam que aquilo que podemos ver, ouvir, degustar, cheirar e tocar quando estamos acordados são apenas as túnicas dos seres vivos e dos objetos materiais que habitam este mundo. Esses outros seres e objetos também têm vitalidades, as quais chegam a ser percebidas pela vitalidade de uma pessoa apenas em circunstâncias muito específicas. As vitalidades de seres não humanos e objetos dispóem de forma corporal - humana, em todos os casos - e mesmo de capacidades sensórias, mas carecem, ao menos do ponto de vista yanesha, de corporalidade.

\section{Teorias da percepção}

Em termos de idéias relativas ao modo como o conhecimento é produzido, os Yanesha estão mais próximos de Platão do que de Aristóteles. $\mathrm{Na}$ filosofia aristotélica, a percepção sensorial fornece a base para todo conhecimento. Argumenta-se que o mundo físico está constituído por 
objetos, os quais se compõem de substância - a matéria de que são feitos - e de forma, isto é, seu aspecto. Por meio dos sentidos, que apreendem a forma dos objetos materiais, os indivíduos coletam informaçôes sobre o mundo. Assumindo a condição de perceptos, essas informações sensoriais correm pelo sistema sangüíneo até o sensus communis, a principal faculdade perceptiva, segundo Aristóteles. Situado na região do coração, o sensus communis tem como a mais importante de suas funções discriminar os perceptos que recebe dos distintos órgãos dos sentidos. Com o auxílio do intelecto - que, para Aristóteles, é a faculdade que nos permite conhecer, entender e pensar -, as informações são avaliadas e interpretadas. Essa visão aristotélica, ligeiramente alterada, fundamenta o pensamento científico atual; nela, o conhecimento resulta do processamento das informaçôes sensoriais pelo intelecto, ou razão.

Platão, por seu turno, faz uma clara distinção entre o "mundo sensível", da percepção, e o que chamou de "mundo inteligível”, o mundo das Formas abstratas. $\mathrm{O}$ mundo sensível caracteriza-se por alteração e mutabilidade contínuas - é um mundo de aparências. Platão defende que o conhecimento deve tomar como objeto o genuinamente real, e não as meras aparências. Afirma que, por meio da apreensão sensorial do mundo físico, não se pode atingir um conhecimento realmente significativo. Para tanto, há de se aplicar a razão ao entendimento dos elementos constituintes do mundo real: as Formas eternas, ou essências, entidades abstratas que existem independentemente do mundo sensível. Os objetos comuns, sendo imperfeitos e mutáveis, são cópias distorcidas de Formas perfeitas e imutáveis. Dado que possuímos uma noção de Formas abstratas, tais como "laranja", "mesa" ou "justiça”, e dado que os sentidos corpóreos são meios imperfeitos de conhecê-las, Platão sustenta que a apreensão do mundo real só é possível por meio da alma. 
A semelhança entre as teorias do conhecimento yanesha e platônica não avança mais do que isso. Conforme assinalado por Descola (1996, p. 375), devemos manter postura de cautela diante do tipo de platonismo ingênuo às vezes atribuído aos povos ameríndios. Platão sugere que a noção das Formas abstratas que compóem o mundo real acompanhanos desde o nascimento. Se é assim, e se os sentidos corpóreos são incapazes de apreender tais Formas, somos levados a inferir, primeiro, que a alma precede o corpo, isto é, que ela há de ser eterna e imortal, e, segundo, que o conhecimento precede a existência do corpo, só podendo ser apreendido como reminiscência de uma vida passada.

Os Yanesha também têm como certo que yecamquëñ (nossa alma/ vitalidade) é eterna e imortal, e que é unicamente por meio de sua agência que se chega ao conhecimento que importa. No entanto, na medida em que consideram as vitalidades como meras manifestaçóes de camuequeñets - o sopro/força vital dos deuses criadores -, e não como entidades discretas e imutáveis, rejeitam nelas a capacidade de passar de um morto a um recém-nascido ou de transmitir conhecimento daquele a este. Os Yanesha acreditam, muito noutra direção, que a vitalidade é insuflada pelos deuses criadores em todo recém-nascido, e que, com a morte do indivíduo, ela retorna à fonte divina de onde provém - a qual se situa em Yomporesho, a morada celestial dos deuses criadores. As vitalidades, portanto, estão em circulação e transformação contínuas: de um estado divino genérico, passam a uma forma humana individualizada, e daí voltam ao estado genérico. Desde esse ponto de vista, o conhecimento não pode ser uma reminiscência do passado: o conhecimento já existente pode passar, por ensino e aprendizagem, de uma pessoa a outra, mas a produção de novos conhecimentos é sempre um feito individual. Só se produzem novos conhecimentos por ação da vitalidade de um indivíduo; com a morte, eles se perdem, a menos que tenham sido ensinados a outrem. 


\section{A produção do conhecimento}

$\mathrm{Na}$ perspectiva yanesha, o conhecimento (eñoteñets) tem sempre um caráter extraordinário, derivando de seres idem, habitantes de outros níveis cósmicos. É bem verdade que os Yanesha dispõem de um notável volume de informações que consideraríamos empíricas, cobrindo um amplo leque de áreas: agricultura e astronomia, botânica e zoologia, hidrologia e meteorologia, navegação e arquitetura, medicina e uso de venenos. Sem dúvida, esse é o resultado de séculos de acumulação de conhecimento empírico, ao longo de incontáveis gerações de Yanesha. Contudo, se se perguntasse aos Yanesha como esse conhecimento teve origem, nenhum deles mencionaria a observação paciente, a recordação e a interpretação de fatos naturais. Tampouco ocorreria de alguém atribuir tal conhecimento à experimentação por tentativa e erro, ao acúmulo coletivo e transgeracional de seus resultados. O genuíno conhecimento, ponderariam os Yanesha, sempre provém de outros níveis cósmicos, o que vale até mesmo para saberes relativos a tarefas bastante básicas em sua experiência de vida, como o cultivo da mandioca, obtido de Agouti, o uso do veneno de pesca barbasco, derivado do sêmen do lascivo gigante Hua'tenañ, e os processamentos do sal e do ferro, aprendidos com os generosos Posona' e Asreso.

Esse tipo de conhecimento foi entregue à coletividade yanesha em tempos míticos. No presente, adquire-se conhecimento extraordinário de modo direto, em virtude de esforços próprios, ou indireto, recorrendo-se a pessoas sábias, geralmente mais velhas. Em ambos os casos, entende-se o processo de aprendizado como uma busca de conhecimento, para a qual o buscador (ou buscadora) deve preparar-se tanto física como espiritualmente. É por isso que, em relação à aquisição de conhecimento, acredita-se, primeiro, que ela só pode ser lograda pela mediação da 
vitalidade do indivíduo e, segundo, que é uma empreitada perigosa, devendo acompanhar-se por crescentes formas de autocontrole. ${ }^{7}$

Os sonhos constituem uma importante fonte de conhecimento, disponível a todos: homens e mulheres, velhos e jovens. Os Yanesha afirmam que, quando estamos dormindo, nossas vitalidades separam-se de nossos corpos e vagam por este mundo e por outros níveis cósmicos. Nossos sonhos refletem as perambulações de nossas vitalidades e os encontros que elas mantêm com seres de caráter normalmente imperceptível: vitalidades de outros seres humanos; sombras de pessoas mortas; almas primordiais de animais, plantas ou objetos; além de uma vasta legião de seres espirituais e divindades. Sonhos podem ser todavia enganadores, e o conhecimento que se obtém por seu intermédio talvez seja mero acaso. Essa dimensão de aleatoriedade só pode ser inferida pelas vitalidades quanto a pequenas porçôes do conhecimento que encontram em suas andanças por outros níveis cósmicos. A menos que as pessoas se adestrem para o "lúcido sonhar", isto é, para se manter lúcidas enquanto sonham e atuarem conscientemente na alteração do rumo dos acontecimentos oníricos (ver Santos-Granero, 2003), suas vitalidades são incapazes de produzir conhecimento, podendo apenas recebê-lo passivamente.

Para obter novos conhecimentos, os Yanesha têm de buscá-los. Essas buscas podem ser breves, simples, com diferentes objetivos específicos ou, então, empreitadas duradouras, a exigir maiores doses de concentração e de empenho pessoal. Adultos lançam-se em buscas do tipo simples diariamente, a exemplo do caçador que masca folhas de coca para pressagiar a presa que apanhará, ou da mulher que, prestes a colher mandioca, canta louvores a Agouti a fim de que este ser lhe indique em quais pés há de encontrar os maiores tubérculos. Essas buscas diárias por conhecimento não requerem muita preparação ritual. Quase todos os adul- 
tos yanesha sabem como promover adivinhações com folhas de coca, e muitos deles conhecem cantos mágicos destinados a fazer com que seres extraordinários forneçam-lhes orientações.

A obtenção de outros tipos de conhecimento pede, por contraste, buscas mais longas e um grau mais elevado de comprometimento pessoal. No curso dessas outras buscas, geralmente associadas a rituais de iniciação, os meninos e as meninas envolvidos esforçam-se para aprender dois tipos de conhecimento: o que é ministrado por seus pais e parentes próximos, e o que é adquirido mediante suas próprias indagações pessoais. Ambos requerem preparativos rituais e orientação a cargo dos mais experientes. Quanto à arte da caça, são as figuras dos pais, avôs e tios paternos que se encarregam do treinamento dos rapazes, que devem seguir um número considerável de proscrições e prescrições alimentares. Recebem a planta mágica epe' (Cyperus sp.) para que a masquem junto com folhas de coca e mantenham, então, estado de vigília. Também têm de dirigir súplicas a certos seres extraordinários, para que estes aceitem guiá-los: Rrera, a harpia, mestre de todos os animais e excepcional caçadora, e Pueyomp, o primordial caçador mítico. Tais seres apresentam-se aos aprendizes - ou melhor, a suas vitalidades - em vigílias rituais ou em sonhos, a fim de lhes conceder especiais conhecimentos venatórios ou preciosos amuletos de caça.

Os rituais pubertários femininos também envolvem busca de conhecimento. No passado, o confinamento pós-menarca das garotas, numa pequena cabana de folhas de palmeira, estendia-se por mais de um ano, hoje, não dura mais do que dois meses. No período de reclusão, as jovens aprendem grande parte daquilo que uma mulher adulta yanesha necessita saber. De suas avós, mães e tias maternas, recebem lições diárias sobre como fiar algodão, tecer, fazer cestos e esteiras, preparar bebida fermentada de mandioca, cuidar da roça e de crianças. Nesse treinamento, transmitem-se não apenas as habilidades físicas necessárias para 
Revista de Antropologia, São Paulo, USP, 2006, v. 49 no 1.

realizar cada uma dessas atividades, mas também os "segredos", ou seja, os conhecimentos extraordinários necessários para que a garota seja bemsucedida em todas elas. Tais segredos incluem execuçōes de cantos destinados a fazer que a mandioca e outros cultivares cresçam em abundância; usos de ervas indutoras ou preventivas da gravidez e da planta mágica epe', capaz de contribuir com a manutenção da saúde das crianças; treinamento de cães de caça; e, ainda, formas de intervenção para que o amor do homem por sua esposa se conserve. A fim de que seu poder de concentração aumente, as meninas reclusas têm de se manter em estado de vigília e observar silenciosos rituais. Mascam muita coca e estão sujeitas a rigorosas restrições alimentares. Durante vigílias rituais ou sonhos, recebem de seres extraordinários importantes informações que se tornam parte de seus patrimônios pessoais de conhecimento.

Buscas de conhecimento ligadas a rituais de iniciação podem exigir bastante dos envolvidos, mas as mais demandantes são as que se referem a conhecimentos especializados. Para se tornar um conhecedor de plantas (apartañ), um xamã de tabaco (pa'llerr) ou um xamã de ayahuasca (ayahuasquero), o aprendiz deve enfrentar um custoso período de treinamento, sob a orientação de um especialista já estabelecido. No passado, os cornesha', modalidade de sacerdotes, tinham de passar por treinamento similar; aprendizes de cornesha' recebiam importantes conhecimentos de seus instrutores, como continua a ocorrer com os candidatos às demais especialidades. À diferença de outros tipos de treinamento ritual, o êxito de um sacerdote cornesha' dependia, em larga medida, de sua capacidade de adquirir conhecimento na forma de revelaçóes pessoais - e o mesmo se aplica, ainda hoje, ao êxito de xamãs. Todos os treinamentos especializados aqui referidos incluem o mascar de folhas de coca e a prática ritual de jejuns e vigílias prolongados; em alguns deles, acrescentase a ingestão de substâncias narcóticas ou alucinógenas. Qualquer uma dessas práticas, afirmam os Yanesha, provoca uma situação de separação 
de nossas vitalidades em relação a nossos corpos, mas o que então se dá é diferente do que se passa na esfera onírica. Nos sonhos, as vitalidades geralmente não obedecem à vontade consciente da pessoa; já com a sustentação do estado de vigília e a ingestão de substâncias tóxicas, elas podem ser conscientemente dirigidas pela pessoa, que recorre, para tanto, ao vigor de seus pensamentos.

Os Yanesha afirmam que, para se obter conhecimento espiritual seja com pessoas sábias ou com seres extraordinários -, deve-se concentrar a vontade própria naquilo que se quer conseguir. Como se trata de uma cultura oral, o processo de aprendizado é entendido como a memorização de pensamentos (yö̈hreta yocsapech). Quanto mais pensamentos uma pessoa acumula no seu coração, mais forte ela se torna. Acredita-se que o poder de uma pessoa sábia deriva do vigor de seus pensamentos (buomenc poctapñot). Recorrendo a tal vigor, aprendizes de xamã e de sacerdote (cornesha) são capazes de dirigir suas vitalidades no rumo que quiserem.

\section{A vitalidade e seus sentidos}

As vitalidades, por um lado, e os corpos que elas provêem de energia, por outro, têm o mesmo conjunto de sentidos. Todavia, diferentemente dos sentidos físicos, os sentidos não corpóreos, próprios a nossas vitalidades, são capazes de apreender a dimensão espiritual dos seres e objetos deste mundo e de outros níveis cósmicos. Sentidos corpóreos e não corpóreos não são intrinsecamente diferentes - operam dos mesmos modos e se classificam segundo hierarquias de importância semelhantes. Isso não é de surpreender, já que, como vimos, é a vitalidade, ou alma, que dota a pessoa de uma vida sensória. A audição é considerada o principal órgão sensorial das vitalidades. Da perspectiva yanesha, os 
Revista de Antropologia, São Paulo, USP, 2006, v. 49 no 1.

mais importantes conhecimentos espirituais são recebidos de seres idem, seja em sonho, seja sob o efeito de alucinógenos, na forma de revelações audíveis. Trata-se de algo que é igualmente verdadeiro para muitos outros povos ameríndios, como os Wakuénai (Hill, 1993, p. 214) - da mesma família lingüística (Arawak) que os Yanesha - ou os Achuar, Shuar e outros grupos Jívaro, cujas mal denominadas "buscas de visão" têm como meta, na realidade, receber, da alma arutam de algum poderoso antepassado, uma mensagem ou profecia (Taylor, 1996, p. 208-9). É pela agência sensorial da vitalidade de uma pessoa, em todos esses casos, que a aquisição/produção de conhecimento está mediada.

Entre os Yanesha, xamãs e sacerdotes (cornesha) esforçam-se para convencer animais, espíritos ou divindades a compartilhar consigo cânticos mágicos, canções sagradas, profecias ou outras mensagens formais. Jeñari, um velho xamã de renome, contou-me que na juventude, durante o seu treinamento, fora instruído a manter prolongadas vigílias a fim de receber a orientação de espíritos familiares. Depois de um tempo mascando coca misturada com suco concentrado de tabaco diariamente, começara a ouvir o canto da mucura e de outros animais. Quando algo assim acontece, disse-me ele, deve-se adotar extremo cuidado, porque pode tratar-se de um espírito mau a imitar determinado animal. Se o caso for este, de embuste, e o indivíduo prestar atenção aos cantos, o espírito mau pode roubar sua vitalidade, o que o levaria à morte. É apenas depois de ter ouvido o mesmo canto por dez vezes que um aprendiz deve começar a repeti-lo e aprendê-lo, o que consiste na maneira de atrair o animal que é dono do canto, de conduzi-lo à condição de amigo e protetor espiritual (Santos-Granero, 2007). Os aprendizes que conquistam seus primeiros espíritos familiares também adquirem, nesse processo, uma nova entidade incorpórea. Chamada chañapchenaya, essa alma é capaz de assumir as formas dos animais que protegem cada xamã yanesha. Os xamãs são os únicos Yanesha que possuem chañapchenaya 
e que, graças a ela, podem transformar-se nos seres de quem são amigos - os mais importantes destes são jaguares, beija-flores e anacondas -, mas também ocorre de os xamãs adotarem outras formas, como as do ar, do vento ou da neblina. Encorporado como um dos seus amigos, o xamã não só adquire as capacidades e os hábitos do animal em questão, mas também a "perspectiva” que lhe é própria. Assim, quando estão vagando sob a forma de jaguares, os xamãs yanesha vêem humanos como animais de presa e podem atacá-los. ${ }^{8}$

Candidatos a sacerdote cornesha' também buscavam revelações de caráter audível. Contudo, em vez de recorrer a espíritos de animais e vegetais, dirigiam súplicas aos deuses criadores - especialmente a Yompor Ror (Sol) - ou a espíritos amigáveis mellañoteñ. Esses seres benévolos só aparecem para os Yanesha que sejam seus devotos, isto é, para aqueles que estejam empenhados em obter sua orientação por meio da prática regular de jejuns, vigílias, rezas, oferendas e bons pensamentos, e de uma postura de amor sofrente. No caso de as divindades considerarem que há um genuíno esforço dos devotos, manifestam seu amor/compaixão por eles revelando-se-lhes por meio de palavras - revelaçóes que podem vir como canções, conselhos ou outras modalidades discursivas formais. Os sacerdotes cornesha' alegavam ouvir, durante vigílias ou em sonhos, as vozes das divindades. As mensagens recebidas podiam ser anúncios de que Yompor Ror ou um de seus emissários estava por chegar, a fim de tornar os Yanesha imortais, ou ser advertências sobre iminentes catástrofes, que as divindades providenciariam para punir suas criaturas humanas por faltas cometidas. Cantos sagrados (coshañnats), revelados a conscienciosos sacerdotes e posteriormente transmitidos a outras pessoas, eram especialmente apreciados e entoados pelos Yanesha, para louvar as divindades e rogar pela salvação coletiva durante certos eventos que celebravam em seus templos (Smith, 1977). 
Embora menos capital do que a audição, a visão também é importante para que nossas vitalidades possam obter conhecimento significativo. O desenvolvimento da capacidade de conduzir nossas vitalidades aos lugares que se deseje é um aspecto relevante do treinamento xamânico yanesha, obtido por meio de jejuns, vigílias e/ou ingestão de narcóticos e alucinógenos. Os aprendizes de xamãs são ensinados a abandonar seus corpos e a viajar a regiōes ocultas - deste próprio mundo e também de níveis cósmicos acima ou abaixo dele. Os xamãs yanesha dizem que, durante esses vôos da alma, vêem animais, espíritos, vegetais e objetos "como estes realmente são", isto é, podem ver as vitalidades de forma humana de todos eles. Nos estados mencionados, os xamãs percorrem diferentes montanhas onde moram os "donos" de determinadas espécies animais. Visitam suas residências, bem como as habitações montanhosas de seres espirituais cuja orientação é crucial para as práticas xamânicas de cura, como é o caso da Mãe da Medicina Vegetal. Noutras ocasiões, visitam o mundo subaquático, e por lá conversam com as sereias ou com as formas humanas dos donos de certas espécies de peixe. Também passam por cavernas habitadas pelas sombras dos mortos que foram corretos em vida, local em que podem encontrar determinadas doenças, como a varíola, em sua forma humana.

Para buscas sacerdotais de conhecimento, a visão não era tão importante quanto a audição. Os Yanesha afirmam que ninguém pode ver as divindades: para vê-las, teria de se praticar uma vigília eterna, o que é o mesmo que colocar a imortalidade como condição para tal. Os sacerdotes de antigamente também mascavam folhas de coca juntamente com suco concentrado de tabaco; à diferença dos xamãs, porém, não realizavam vôos anímicos, tampouco procuravam familiarizar animais consigo. Alguns cornesha', contudo, podiam descobrir açóes ameaçadoras de espíritos maus jo' ou demônios oneñet em determinados lugares e re- 
chaçá-las. Também se diz que espíritos amigáveis mellañoteñ às vezes se deixavam ver por sacerdotes que fossem especialmente dedicados. No fim das contas, contudo, os cornesha' pouco dependiam da visão como fonte de conhecimento. Para que pudessem aprender e memorizar informações orais, atribuíam importância muito maior à audição e à força dos seus pensamentos, o que era especialmente relevante no aprendizado dos cantos sagrados coshaññats - de mais de 75 versos em alguns casos (Smith, 1977, p. 282).

Os sentidos do olfato, paladar e tato de nossas vitalidades são muito menos relevantes como fontes de conhecimento. Alguns xamãs mencionaram para mim os olores agradáveis das mulheres que haviam encontrado em seus vôos anímicos. Outros descreveram como saborosa e aromática a comida que tinham sido convidados a provar quando em visita às casas de seres extraordinários. Em acréscimo, os xamãs yanesha atribuem alguns fedores à presença de espíritos maus e de demônios, e dizem que certas fragrâncias são uma clara evidência de que determinados objetos foram magicamente trabalhados para servir como amuletos. Do mesmo modo que os Muinane (Londoño Sulkin, comunicação pessoal), os Yanesha consideram que odores podem influir sobre a subjetividade, às vezes enfurecendo e pervertendo as pessoas e, em outros casos, restaurando seu discernimento moral. Isso é especialmente verdadeiro quanto ao sangue menstrual, capaz de debilitar xamãs e caçadores, e mesmo de despojá-los por completo de seus poderes mágicos (ver Belaunde, neste volume). A detecção de cheiros permite que as pessoas tomem medidas defensivas contra seres malévolos e contra objetos perigosamente encantados. Em termos gerais, no entanto, esses sentidos entre os Yanesha não desempenham papel relevante na aquisição/produção de conhecimento misterioso, ao contrário da audição e da visão. 


\section{Percepção e perspectivismo}

A noção de "perspectivismo" ameríndio (Århem, 1993; Stolze Lima, 1999, 2000, 2005; Viveiros de Castro, 1998, 2004a, 2004b) abriu novas e estimulantes sendas de investigação no campo dos estudos amazônicos. No entanto, ela tem gerado pouca discussão sobre dois aspectos que mereceriam estar no centro do debate: o papel dos diferentes sentidos nas relações intra e interespecíficas e, em segundo lugar, a questão da consciência dos seres - consciência tanto de que almas encorporadas e desencorporadas têm diferentes capacidades sensórias como de que a percepção tem um caráter perspectivo.

A dimensão sensorial do fenômeno do perspectivismo não foi explorada por seus estudiosos, exceto no que concerne à afirmação de que os ameríndios atribuem a animais, espíritos e outros seres não humanos as mesmas faculdades cognitivas e sensoriais que eles, ameríndios, possuem (e.g. Viveiros de Castro, 1998, p. 474). Esses autores têm posto o foco sobretudo na visão e em como diferentes tipos de seres "vêem" outros seres. Alguém poderia argumentar que a noção de perspectiva é sinônimo de ponto de vista, o que, portanto, justificaria o foco na visão. Entretanto, dada a ênfase na "condição encorporada" da perspectiva e na noção de corpo como "feixe de afecções e capacidades", esperar-se-ia uma perspectiva menos "visocêntrica" da própria perspectiva. Assim, a atribuição à visão do papel de meio por excelência de constituição de relaçôes entre diferentes seres, em detrimento dos outros sentidos, parece ser uma projeção da hierarquização dos sentidos que nós próprios, ocidentais, temos. Para os Yanesha, assim como para muitos outros povos ameríndios, a audição é uma forma de percepção e um modo de conhecimento mais importante do que a visão - e do que qualquer um dos demais sentidos -, o que se aplica a contextos relacionais tanto intra como interespecíficos. O termo kayapó mar, que significa simultanea- 
mente "ouvir" e "saber-conhecer-entender", é uma expressão dessa difundida concepção (Murphy, 2004, p. 43). Noções similares encontram-se entre os Suyá, para quem ku-mba significa "ouvir-entender-saber-conhecer” (Seeger, 1981, p. 83), e entre os Pa'ikwené, que traduzem o termo tchimap por "ouvir-escutar-prestar atenção-entender" (Passes, 1998, p. 46 e neste volume).

Pouca atenção vem sendo dada, de modo análogo, às diferenças entre os vários componentes da pessoa quanto a suas capacidades sensórias - o que tem uma importância ainda maior - e aos graus de consciência de distintos tipos de ser em relação a essas diferenças. Os estudiosos do perspectivismo reconhecem a difundida e "animista" noção ameríndia de que todos os seres compóem-se de um corpo e de uma ou mais almas, mas tomam por certo que diferentes seres tenham capacidades sensórias similares. Na versão radical do perspectivismo que Viveiros de Castro advoga, todos os seres vêem-se como humanos e vêem todos os outros como os contrários estruturais de si mesmos. "Em condiçôes normais", diz o autor, "os humanos vêem os humanos como humanos, os animais como animais e os espíritos (se chegam a vê-los) como espíritos; animais (predadores) e espíritos, no entanto, vêem os humanos como animais (de presa), do mesmo modo que os animais (de presa) vêem os humanos como espíritos ou como animais (predadores)" (Viveiros de Castro, 1998, p. 470). Em circunstâncias outras, não ordinárias, entretanto, as almas de todos os seres vêem a si mesmas, bem como as almas de outros tipos de criaturas, como seres humanos. Isso está em consonância com o que Viveiros de Castro chama de caráter "multinaturalista" das ontologias ameríndias, algo que pressupóe um constraste entre a unidade espiritual de todos os seres - têm, todos eles, uma alma humana - e sua diversidade corpórea: diferentes categorias de seres têm diferentes tipos de corpos. Do ponto de vista ameríndio, a diferença de perspectiva residiria, portanto, no corpo. 
Revista de Antropologia, São Paulo, USP, 2006, v. 49 no 1.

A suposta unidade espiritual de todos os seres já foi contestada de modo convincente tanto por Londoño Sulkin (2005 e neste volume) como por Rosengren (neste volume). Rosengren argumenta que almas não são genericamente humanas e, sim, bastante particularizadas, em conseqüência de condições individuais, sociais e históricas relativas a cada espécie. Londoño Sulkin sustenta que almas e corpos de espécies distintas diferem em termos das substâncias com as quais são feitos, traço responsável por sua maior ou menor moralidade. Aqui, eu gostaria de contribuir para essa discussão introduzindo a variável da consciência consciência não só de que as faculdades sensoriais de almas encorporadas, por um lado, e desencorporadas, por outro, são diferentes, mas consciência também de que diferentes tipos de seres têm diferentes capacidades cognitivas. $\mathrm{O}$ perspectivismo radical admite que almas encorporadas e desencorporadas têm diferentes habilidades sensórias: enquanto as primeiras vêem-se como humanas e vêem outros tipos de seres como seus opostos estruturais, as últimas vêem a si mesmas e a todas as almas desencorporadas na forma de ser humano. $\mathrm{O}$ que não está claro é se todos os seres são igualmente conscientes, primeiro, da unidade espiritual entre eles e, segundo, do caráter perspectivo da percepção. Se os ameríndios afirmam que todos os seres percebem a si mesmos como humanos e percebem outros como animais ou espíritos, também sustentam que os humanos têm a capacidade de perceber a dimensão espiritual humana de todos os seres. Essa aptidão é sempre atribuída a um dos componentes não corpóreos da pessoa: yecamquëñ, entre os Yanesha; bedu yushin, entre os Kaxinawa; mekarõ, entre os Kayapó; likáriwa, entre os Wakuénai; ou wakan, entre os Jívaro. Acredita-se que apenas esses componentes estão dotados das faculdades e da agência sensoriais que permitem perceber a dimensão espiritual do mundo e, assim, engajar-se na aquisição/produção de conhecimento. Ainda que vejam animais como animais, espíritos como espíritos, os humanos sabem 
que tanto os primeiros como os últimos têm almas de forma humana; e também se sabem capazes de, mediante a agência de suas próprias almas ou vitalidades, interagir com esses outros seres.

É duvidoso, entretanto, que animais e espíritos tenham uma capacidade de discernimento similar, o que poderia ser a principal diferença entre humanos atuais e "primordiais", ou "ex-humanos". Humanos são humanos porque sabem - isto é, porque possuem a capacidade sensorial não corpórea para saber - que a dimensão material do mundo encobre uma dimensão espiritual formalmente diferente de si mesma, e que a percepção física tem sempre um caráter perspectivo. Não parecem sabêlo animais, espíritos e outros seres não humanos, e aí reside sua distinção em relação aos humanos. Somos informados de que jaguares vêem humanos como pecaris, e que pecaris vêem humanos como jaguares; mas saberão jaguares e pecaris que a dimensão espiritual dos animais que vêem é humana? Saberão eles que a percepção de caráter perspectivo é também multidirecional? Ao nos basearmos no que vai aqui reunido, a resposta é não.

Segundo Stolze Lima (2000, p. 50), por exemplo, "o pecari se sabe humano, sabe que um Juruna é um semelhante, mas não sabe que é um pecari para os Juruna”. O que distingue humanos de animais ou de espíritos é, sobretudo, que os primeiros estão cientes do caráter perspectivo da percepção, ao passo que os demais não. É bem possível que isso seja um efeito do fato de animais e espíritos terem constituições diferentes carecem seja de almas próprias, seja de corpos próprios - e, portanto, modos diferentes de sentir e conhecer. Em muitas sociedades ameríndias, acredita-se que animais não tenham almas individuais próprias (Viveiros de Castro, 1998, p. 471), mas, sim, que sejam manifestações individuais da alma primordial de cada espécie, freqüentemente conhecida como "mestre", "dono" ou "mãe" da espécie. Os espíritos, por sua vez, carecem de corpo próprio: é verdade que têm forma física e que não 
são, como aponta Viveiros de Castro (id., p. 481), completamente imateriais, mas lhes falta o tipo de vida corpórea ou sensória que é característico dos humanos vivos. Privados de almas próprias ou de corpos próprios, esses seres, embora dotados de perspectiva, ignoram que outros seres também o são. É esta capacidade - a de estar ciente do caráter perspectivo da percepção - e este saber - quanto à essência humana de todos os seres - o que animais e espíritos perderam, ou não adquiriram, quando transformados em tais ao final dos tempos míticos.

É por essa razão que não se pode dizer que os povos ameríndios pensam que os animais são humanos; o que eles antes sustentam é que "os animais pensam que são humanos", como bem expressou Stolze Lima (1999, p. 113). Isso coloca em questão a versão radical do perspectivismo, que conduz à inferência de que todas as perspectivas têm o mesmo valor (Århem, 1993, p. 124), mas não à inferência oposta, a saber, a de que existe uma perspectiva absoluta: humanos, animais e espíritos podem impor suas perspectivas uns aos outros, mas o resultado de tal troca de perspectivas não pode, como argumenta Stolze Lima (2000, p. 48), ser determinado a priori. $\mathrm{O}$ fato de os animais "pensarem que são humanos" mas ignorarem que os humanos são humanos está antes a indicar que, nas cosmologias ameríndias, a consciência do caráter perspectivo da percepção só é atribuída aos seres humanos atuais. Isso, por sua vez, sugere duas coisas. Primeiro, que é possível que muitos povos ameríndios tenham visōes de mundo mais antropocêntricas - se, com o prefixo "antro", queremos dizer humanos atuais, em oposição a humanos de tempos primevos - do que estamos preparados para aceitar (Viveiros de Castro, 1998, p. 477). .' Segundo, que, em vez de defender um tipo único e monolítico de perspectivismo ameríndio, seria melhor falar de uma variedade de cosmologias perspectivistas, todas elas compostas de um mesmo núcleo de elementos perspectivos, mas estes se arranjando, em cada uma, segundo diferentes permutaçóes de lugar e de pesos relativos 
(Londoño Sulkin, 2005, p. 24; Stolze Lima, 2000, n. 6). Desde o ponto de vista dessas formas menos radicais de perspectivismo, temos que é a ilusão em que vivem os animais - a que os leva a pensar que são humanos - que faz da vida humana algo tão perigoso (Stolze Lima, 1999, p. 113). Esse perigo acentua-se ainda mais pelas deficiências que os ameríndios atribuem às faculdades sensoriais - tanto às corpóreas como às não corpóreas.

\section{Deficiências perceptivas}

As diferenças que os Yanesha atribuem às vitalidades encorporadas e desencorporadas em termos de suas capacidades sensórias confluiriam para um apurado sistema de conhecimento e percepção - isto, se não fossem dois problemas. Da perspectiva yanesha, nem os sentidos corpóreos nem os não corpóreos são infalíveis, sendo mais bem imperfeitos, deficientes - passíveis, portanto, de errar. Em segundo lugar, as dimensões material e espiritual do mundo não são autocontidas e estritamente separadas uma da outra. Elas até podem ter existências paralelas, mas, ao não nutrirem descontinuidades entre si, são uma única e mesma coisa. Por conta disso, ocorre freqüentemente de vitalidades encorporadas e desencorporadas de diferentes seres entrarem em contato de maneiras que transgridem os modos normais de percepção - "normais" no sentido de corpóreos e vigentes durante a vigília corriqueira. Ambas as situações, de falha e de transgressão perceptiva, trazem consigo sérios riscos para os seres em relação.

Os Yanesha têm o cuidado de indicar que a percepção sensorial, seja ela corpórea ou não corpórea, pode ser enganadora. No dia-a-dia, há muitas situações em que os sentidos físicos enganam uma pessoa, e os Yanesha acreditam, ademais, que também os sentidos de suas vitalida- 
des são imperfeitos. Dizem, por exemplo, que, quando os aprendizes de xamã estão na montanha, em visita à casa de Shemellama'yarr - o jaguar preto Vespa-Que-Pica, dono da variedade de tabaco de flores vermelhas, usada por feiticeiros para produzir encantamentos -, porções de carne lhes são oferecidas por jaguares em forma anímica humana - a carne, defumada ou assada, parece ser de caça, mas é, na verdade, de gente. Se algum aprendiz ingênuo ou imprudente aceita e come a oferenda dos jaguares, desenvolve um intenso desejo por carne humana. A partir de então, a cada vez que deseja comer carne, sua alma chañapchenaya transforma-se num jaguar devorador de gente.

Encontros com seres espirituais durante vôos de alma também podem reservar embustes. Quando a vitalidade de um xamã visita outros planos cósmicos, seus sentidos só podem perceber as formas anímicas humanas dos habitantes locais, mas não os corpos com que estes se apresentariam ao xamã enquanto ele estivesse em estado normal de vigília: corpos inumanos. Assim, não é sempre que os xamãs podem distinguir os diferentes seres que encontram em seus vôos anímicos. ${ }^{10}$ Belas mulheres de cabelos longos, túnicas brilhantes, pinturas graficamente intricadas e colares de sementes aromáticas podem ser uma fêmea de jaguar, uma sereia, a mãe da ayahuasca, a filha do Tapir primordial ou um espírito mellañoteñ feminino. Com o tempo, os xamãs aprendem a distinguir uma manifestação da outra pelos ornamentos que utilizam e, em particular, pelos padrões de suas túnicas; no período de seu treinamento, porém, a inexperiência pode levá-los a ter relaçóes sexuais com qualquer uma dessas mulheres. Se a mulher em questão for um espírito bondoso, o encontro pode ser não apenas prazeroso, mas altamente benéfico: o aprendiz de xamã pode obter com ela conhecimentos extraordinários de grande valor. Mas, se a mulher é um espírito mau ou uma fêmea de jaguar devorador de gente, ela pode roubar a vitalidade do aprendiz, o que o levaria à morte. 
A transgressão perceptiva é igualmente arriscada. Normalmente, a forma da alma de um outro ser só é perceptível aos sentidos não corpóreos; percebê-la com os sentidos corpóreos é sempre perigoso. Foi isso o que aconteceu comigo quando, conforme o relato que abriu este artigo, ouvi a música das subaquáticas Pocoy, o que explica a ansiedade de Matar em ter me levado embora o mais rápido possível. Quando um pescador yanesha some e seu corpo nunca mais é encontrado, o desaparecimento é quase sempre atribuído à ação das sereias sedutoras. Os caçadores yanesha também estão sujeitos a esse tipo de encontro, embora, em seu caso, a tendência seja encontrar vitalidades de animais de caça em sua manifestação individual ou almas primordiais de diferentes espécies animais. Esses encontros são sempre perigosos ao promover a passagem das vitalidades encorporadas de humanos a um espaço-tempo liminar, no qual elas entram em contato com as vitalidades desencorporadas de animais. Um caçador alveja um dos tapires "do" Tapir primordial e o abandona gravemente ferido na mata; o Tapir primordial, então, pode revelar-se ao caçador e roubar sua vitalidade como punição por tal falta de consideração. Noutras circunstâncias, a vitalidade de um pecari pode aparecer a um caçador perdido na mata como uma bela mulher, decidida a seduzi-lo e a levá-lo a viver consigo na sua casa na montanha. ${ }^{11}$ Em casos como esses, o caçador adota o ponto de vista do pecari e, com ele, sua forma animal (Viveiros de Castro, 1998, p. 483). Para uma pessoa genérica, portanto, impedir os próprios sentidos corpóreos de perceber as vitalidades de seres que lhe são diferentes é tão importante quanto treinar seus sentidos não corpóreos a identificar a quais corpos, afinal, pertencem as formas anímicas humanas encontradas em sonho. 
Revista de Antropologia, São Paulo, USP, 2006, v. 49 no 1.

Os modos yanesha de sentir e conhecer são muito diferentes dos nossos. Entre sua teoria da percepção e a de Platão, há semelhanças relevantes, mas as diferenças são mais substanciais - quando mais não fosse, porque a segunda carece do caráter perspectivo tão típico de cosmologias ameríndias. Do ponto de vista yanesha, conhecimento que importa é conhecimento extraordinário: que provém da dimensão espiritual do mundo vivido e a ela se refere. Esse tipo de conhecimento não pode ser obtido mediante os sentidos físicos, mas somente pela agência consciente de um dos vários componentes não corpóreos da pessoa. O conhecimento significativo, seja ele obtido diretamente ou aprendido de outros indivíduos, sempre ganha existência por meios não corpóreos de sentir e conhecer. Conforme o convincente argumento apresentado por Belaunde (neste volume) ao discutir a hematologia ameríndia, o conhecimento tem sempre um caráter encorporado; o corpo, porém, é o lócus do conhecimento, não o seu agente causador.

É com o conhecimento adquirido com seres que vivem em outros níveis cósmicos que os ameríndios aprendem a fazer e a refazer corpos humanos. Entre esses povos, é intensamente recorrente a afirmação de que rituais de iniciação, todos eles a comandar algum grau de transformação nos corpos dos iniciandos, foram ensinados por seres extraordinários: Lua, Harpia, Jaguar e assim por diante. Se a obtenção de conhecimento com esses seres é um meio de modelagem e formatação de corpos, a aquisição de novos conhecimentos também induz importantes processos de transformação corporal. Povos jívaro sustentam que homens e mulheres que têm revelações arutam adquirem uma maior autoconfiança, sentimento que se manifesta na sua conduta e nos movimentos de seu corpo; já as pessoas que nunca passaram pela experiência da revelação podem ser identificadas por um comportamento desprovido de altivez, por uma postura carente de imponência. Por esse 
mesmo tipo de transformação corporal, os Yanesha dizem passar certos xamãs e sacerdotes: aqueles que tenham tido êxito na obtenção de alguma revelação sonora - mensagem ou canto - de qualquer um dos muitos animais, espíritos e divindades operadores desse tipo de transmissão. Caiuby (neste volume) discute os processos de desfiguração e refiguração que têm lugar nos rituais funerários bororo, e, conforme sua contundente demonstração, até mesmo os corpos de mortos são transformados por meio de conhecimento ritual. Sobre corpos, então, eu diria que, da perspectiva ameríndia, eles não são causa de conhecimento, mas causados por conhecimento - que se adquire sempre por meio de suas vitalidades sensuais.

\section{Notas}

1 Quero agradecer aos participantes e ao público da "Conference for Students in Appreciation of their Teacher Joanna Overing", por valiosos comentários ao esboço que originou este artigo. Antes daquele evento, mantive um rico diálogo sobre modos ameríndios de conhecimento com George Mentore, a quem também muito devo. Agradecimentos especiais vão a Carlos Londoño Sulkin e Steven Rubenstein, por comentários que ajudaram a esclarecer diferentes aspectos do meu argumento, e a Olga F. Linares, estimada colega e amiga que empenhou seu tempo na revisão do meu inglês.

2 Para noções similares entre outros povos amazônicos, ver Belaunde, Rosengren e Storrie (neste volume).

3 Para concepções ameríndias que diferem dessas, ver Viveiros de Castro (2004b, p. 465) e Vilaça (1992, p. 66, 81).

4 Para idéias similares, ver Overing (neste volume).

5 Como Wittgenstein (1974), alguns autores (Viveiros de Castro, 1998; Stolze Lima, 1999, p. 122) concebem a alma não como entidades imateriais, mas como seres humanos vivos. Na visão desses autores, a equivalência entre corpo e alma - na medida em que o corpo humano é tido como uma imagem da alma humana - 
confere a ela um certo grau de corporalidade. Os Yanesha concordariam que a alma não é imaterial. Ainda assim, há uma clara distinção, por eles traçada, entre a crua e delimitada materialidade de chetsots (o corpo como carne) e a materialidade radiante e difusa de yecamquën (a vitalidade como sopro/força). Com essa distinção, os Yanesha não reconhecem em yecamquëñ qualquer espécie de corporalidade.

6 Para idéias semelhantes entre os Matsigenka e os Airo-Pai, ver Rosengren e Belaunde (neste volume).

7 Sobre os perigos do conhecimento excessivo, ver Overing (1975), Santos-Granero (1991) e Gow (neste volume).

8 Para uma discussão sobre a extrema fluidez e mutabilidade de "corpos" e "almas", ver Werlang (neste volume).

9 Notar, por exemplo, que a maioria dos arrazoados do perspectivismo ameríndio focaliza como os humanos vêem animais e espíritos, e como diferentes tipos de animais e espíritos vêem os humanos; pouco se diz sobre como animais predadores vêem espíritos, como animais de presa vêem animais predadores e assim por diante. As cosmologias ameríndias podem ser multinaturalistas, mas continuam fundadas na centralidade e primazia da humanidade, isto é, da humanidade dos dias atuais.

10 Para noções wari' similares, ver Vilaça (1992, p. 82).

11 Ver Rosengren (neste volume) para casos semelhantes de encontros de caráter liminar.

\section{Bibliografia}

ÅRHEM, Kaj

"Ecosofía Makuna", in CORREA, François (ed.), La selva humanizada: ecología alternativa en el trópico húmedo colombiano, Bogotá, ICA/FEN/CEREC, pp. 109-26.

CLASSEN, Constance

"McLuhan in the Rainforest. The Sensory Worlds of Oral Cultures", in HOWES, David (ed.), Empire of the Senses. The Sensual Culture Reader, Oxford/ New York, Berg, pp. 147-63. 
CROCKER, Jon Christopher

1985 Vital Souls. Bororo Cosmology, Natural Symbolism, and Shamanism, Tucson, The University of Arizona Press.

DESCOLA, Philippe

1996 The Spears of Twilight. Life and Death in the Amazon Jungle, Glasgow, HarperCollins Publishers.

HILL, Jonathan D.

1993 Keepers of the Sacred Chants. The Poetics and Ritual Power in an Amazonian Society, Tucson/London, The University of Arizona Press.

HOWES, David (ed.)

1991 The Varieties of Sensory Experience, University of Toronto Press.

2005 Empire of the Senses. The Sensual Culture Reader, Oxford/New York, Berg.

KENSINGER, Kenneth

1995 How Real People Ought to Live. The Cashinahua of Eastern Peru, Prospect Heights, IL, Waveland Press.

LAGROU, Elsje

$2000 \quad$ "Homesickness and the Cashinahua Self: A Reflection on the Embodied Condition of Relatedness", in OVERING, Joanna \& PASSES, Alan (ed.), The Anthropology of Love and Anger. The Aesthetics of Conviviality in Native Amazonia, London/New York, Routledge, pp. 152-69.

LONDOÑO SULKIN, Carlos

2005 "Inhuman Beings: Morality and Perspectivism among Muinane People (Colombian Amazon)", Ethnos, vol. 70(1): 7-30.

MCLUHAN, Marshall

1961 "Inside the Five Sense Sensorium", The Canadian Architect, vol. 6: 49-54.

MURPHY, Isabel

2004 And I, In My Turn, Will Pass It On. Knowledge Transmission Among the Kayapó, Dallas, TX, SIL International. 
OVERING, Joanna

1975

The Piaroa, A People of the Orinoco Basin. A Study in Kinship and Marriage, Oxford, Clarendon Press.

1985 Reason and Morality, London /New York, Tavistock Publications.

PASSES, Alan

1998

The Hearer, the Hunter, and the Agouti Head: Aspects of Intercommunication and Conviviality Among the Paikwené (Palikur) of French Guiana, tese de doutorado, University of St. Andrews.

2001

"Hearing as Understanding: The Value of Good Listening in Native Amazonia", Paper for Queen's University, Belfast, 9 Oct.

SANTOS-GRANERO, Fernando

1991

The Power of Love: The Moral Use of Knowledge Amongst the Amuesha of Central Peru, London, Athlone Press.

2003 "Pedro Casanto's Nightmares: Lucid Dreaming in Amazonia and the New Age World", Tipiti. Journal of the Society for the Anthropology of Lowland South America, vol. 1(2): 179-210.

2007

"Of Fear and Friendship: Amazonian Sociality beyond Kinship and Affinity", Journal of the Royal Anthropological Institute, vol. 13(1): 1-18.

SEEGER, Anthony

$1981 \quad$ Nature and Society in Central Brazil. The Suya Indians of Mato Grosso, Cambridge, MA, Harvard University Press.

SHEPARD JR., Glenn H.

2004 "A Sensory Ecology of Medicinal Plant Therapy in Two Amazonian Societies", American Anthropologist, vol. 106(2): 252-66.

SMITH, Richard Chase

1977

Deliverance from Chaos for a Song: A Social and Religious Interpretation of the Ritual Performance of Amuesha Music, tese de doutorado, Cornell University.

STOLTZE LIMA, Tânia

1999 "The Two and its Many. Reflections on Perspectivism in a Tupi Cosmology", Ethnos, vol. 64(1): 107-31. 
Santos-Granero, F. Vitalidades sensuais...

2000 "Towards an Ethnographic Theory of the Nature/Culture Distinction in Juruna Cosmology", Brazilian Review of Social Sciences, vol. 1 :43-52.

2005 Um peixe olhou para mim. O povo Yudja e a perspectiva, São Paulo, Editora UNESP.

TAYLOR, Anne Christine

1996 "The Soul's Body and its States: An Amazonian Perspective on the Nature of Being Human", Journal of the Royal Anthropological Institute, vol. 2: 201-15.

VILAÇA, Aparecida

1992 Comendo como gente: formas do canibalismo wari (Pakaa Nova), Rio de Janeiro, Editora UFRJ.

VIVEIROS DE CASTRO, Eduardo

1998 "Cosmological Deixis and Amerindian Perspectivism", Journal of the Royal Anthropological Institute, vol. 4(3): 469-88.

2004a "Perspectival Anthropology and the Method of Controlled Equivocation", Tipiti, vol. 2(1): 3-22.

2004b "Exchanging Perspectives: The Transformation of Objects into Subjects in Amerindian Ontologies", Common Knowledge, vol. 10(3): 463-84.

WITTGENSTEIN, Ludwig

1974

Philosophical Investigations, Oxford, Blackwell. 
ABSTRACT: Yanesha people of eastern Peru would agree with Aristotle and St. Thomas Aquinas in that knowledge can only be achieved through sense perception. They would, however, disagree on what exactly "sense perception" means. In the Western tradition the senses are considered to be the "physiological" modes of perception. We can only know, it is asserted, through the body and its senses: sight, hearing, smell, touch, and taste. In contrast, Yanesha people view bodily senses as imperfect means of knowing, unable to grasp the true, spiritual dimension of the world. Only one of the non-corporeal components of the self, yecamquën or "our vitality", is endowed with the sensory faculties that allow for a correct perception, and thus for the possibility of "true" knowledge. It is for this reason that, from a Yanesha point of view, vitalities are sensual, whereas bodies are considered to be somewhat insensible. This article explores Yanesha non-corporeal modes of sensing and knowing, as well as their theories of perception and sensual hierarchies. My purpose is to advocate for a renewed anthropology of the senses in Amazonian studies, as well as to propose a critical revision of the notion of Amerindian perspectivism.

KEY-WORDS: Amazonia, Peru, Yanesha, personhood, sensory perception, perspectivism.

Tradução de Fernando Fedola L. B. Vianna. Aceito em janeiro de 2006. 